\title{
Green Synthesis of Reduced Graphene Nanostructure from Cinnamomum Camphora
}

\author{
Ramya Athiyanam Venkatesan 1(D), Neethu Joseph ${ }^{2}$ (D), Manoj Balachandran 3,* (D) \\ 1 Department of Physics \& Electronics, CHRIST (Deemed to be University), Bangalore, India; avramyaa1@gmail.com \\ (R.A.V.); \\ 2 Department of Physics \& Electronics, CHRIST (Deemed to be University), Bangalore, India; \\ neethu.joseph@res.christuniversity.in (N.J.); \\ 3 Department of Physics \& Electronics, CHRIST (Deemed to be University), Bangalore, India; manoj.b@ christuniversity.in \\ (M.B.); \\ * Correspondence: manoj.b@christuniversity.in;
}

Received: 24.08.2020; Revised: 1.10.2020; Accepted: 3.10.2020; Published: 6.10.2020

\begin{abstract}
A facile green synthesis for carbon nanoparticle production using Cinnamomum camphora (Camphor) is presented. Camphor upon carbonization and chemical oxidation leads to the formation of nano-carbon structures with lateral size $7.33 \mathrm{~nm}$ to $4.14 \mathrm{~nm}$, respectively. The nanomaterial's stacking height is about $2.76 \mathrm{~nm}$ and $3.10 \mathrm{~nm}$, leading to the formation of about 10 layers of carbon. The AFM analysis confirms that the graphene layer formed is wrinkled or folded. Developments of a layered structure with spheroids are observed on the sample's surface, confirming the graphitization of the amorphous carbon. The relative intensity of the defect to the graphite band is found to be 0.98 for the nanostructure indicating a lesser degree of defects. The $\mathrm{C} 1 \mathrm{~s}$ band of the nanostructure is deconvoluted to components at $284.7,286.5,287.3$, and $289 \mathrm{eV}$, which are assigned to non-oxygenated ring carbon ( $\mathrm{sp}^{2}$ carbon), $\mathrm{C}$ in $\mathrm{C}-\mathrm{O}$ (bound to $\mathrm{O}$ either as epoxy or hydroxyl), $\mathrm{C}$ in $\mathrm{C}=\mathrm{O}$ (of alcohols, phenols or ether), and $\mathrm{C}$ in $\mathrm{C}(\mathrm{O}) \mathrm{O}$ (carboxylic acid) respectively. The study reveals the formation of few-layer oxygenated carbon layers from the botanical hydrocarbon.
\end{abstract}

Keywords: green synthesis; carbon nanoparticle; Cinnamomum camphora; chemical oxidation

(C) 2020 by the authors. This article is an open-access article distributed under the terms and conditions of the Creative Commons Attribution (CC BY) license (https://creativecommons.org/licenses/by/4.0/).

\section{Introduction}

Cinnamomum camphora, belonging to the plant family Lauraceae [1,2], is generally circulated and developed in southern China as a typical Chinese restorative herb. It is utilized mainly by the Chinese community for medication, including rheumatic joint inflammation, muscular strains, stomach torment, rheumatism, joint twists, respiratory illness, and bronchitis [3]. A few sorts of mixes, for example, characteristic camphor, essential oil, lignans, flavones, and polyphenols, have been recently segregated from Cinnamomum camphora [4], and show traces of bioactivities against harmful microscopic organisms [5], poisonous insects [6,7] and human urothelial carcinoma [8]. Plant-based strategies for the reduction of graphene oxide have specific points of interest over microorganism-based techniques. Plant-based synthesis strategies dispense with the requirement for high maintenance cell societies. They can be promptly exploited for large scale manufacturing of graphene [9]. Notwithstanding these focal points, no examinations on screening plants and improvement of response conditions have been accounted for the reduction of graphene oxide utilizing plant extracts. 
There is a need for the growth of naturally amicable graphene synthesis procedures that do not utilize much of harmful and toxic chemicals. Recent reports on the reduction of graphene oxide emphasize on the replacement of traditional reducing agents, with melatonin [10], vitamin C [11], and sugar [12] instead of toxic hydrazine. Organic reduction of graphene oxide utilizing microorganisms [13-15] and plant derivatives [16-18] has been proposed as conceivable eco-friendly options compared to completely chemical and physical synthesis strategies.

Graphene is potentially one of the most energizing materials of the decade. A plain sheet of sp2 hybridized carbon atoms is firmly arranged into a honeycomb lattice [19]. In 2004, graphene's primary disclosure utilizing a scotch tape stripping technique brought a sensational upheaval, particularly in the realm of materials science research and development [20]. Recently, this single carbon sheet has pulled in serious interest among established researchers attributable to the two-dimensional structure of them[21]. It is demonstrated that a perfect graphene sheet is profoundly arranged and shows remarkable practices, including extraordinary surface areas $\left(2630 \mathrm{~m}^{2} \mathrm{~g}^{-1}\right)$, high Young's modulus (1.0 TPa), high thermal conductivity (5000 $\mathrm{W} \mathrm{m}^{-1} \mathrm{~K}^{-1}$ ), and strong chemical toughness. The two primary steps in the chemical strategy for making graphene are the oxidation of graphite into graphene oxide, trailed by reducing graphene oxide into graphene. The most commonly utilized technique to reduce graphene oxide is the Hummers' method [22].

Investigating the unique properties of carbon and graphene-based nanodots has attracted tremendous research interest in recent days due to its unique and extravagant properties. They exhibit fascinating properties like stable fluorescence (FL), chemiluminescence (CL), and electro-chemiluminescence (ECL), taking into consideration their size and edge effect $[23,24]$. Nano-carbon structure has been fabricated from various carbon-based materials like glucose, graphite or graphene oxides, reduced graphene oxide, and carbon fiber by synthesis methods like hydrothermal or electrochemical routes [25,26]. Even though these are facile approaches, the precursors used are relatively costlier. Studies have been reported on the synthesis of carbon-based dots from agricultural waste, hydrocarbon fuel, plant residues, and humic substances, promising agents of the Nanocarbon domain. Synthesis of nano-carbon derivative in a facile way from an environmentally benign way is a topic of interest $[27,28]$. In the present investigation, few-layer graphene is prepared from botanical hydrocarbon-Camphor (CS), an environmentally benign source of Nanocarbon, considering its ease of availability, cost efficiency as well as a comparative decrease in toxicity of chemicals.

\section{Materials and Methods}

For the sample preparation, about $2 \mathrm{~g}$ of camphor soot and sodium nitrate $\left(\mathrm{NaNO}_{3}\right)$ was treated with concentrated sulphuric acid $\left(\mathrm{H}_{2} \mathrm{SO}_{4}\right)$ in an ice bath. Under continuous stirring, about $6 \mathrm{~g}$ of $\mathrm{KMnO}_{4}$ was added slowly. The mixture was then allowed to cool down for 30 minutes. After removing from the ice bath, the solution was stirred continuously for 48 hours using a Teflon coated magnetic stirrer. This was followed by the addition of $184 \mathrm{~mL}$ of distilled water, $560 \mathrm{~mL}$ of warm water along with $40 \mathrm{~mL}$ of hydrogen peroxide one at a time, and the mixture was left undisturbed for 12 hours. The GO particles (CS1) were separated from the solution by centrifugation and washed repeatedly with water and acetone, followed by sonication for 20 minutes. 


\subsection{Characterization techniques.}

The X-ray profiles of the samples were obtained using Bruker AXS D8 Advance X-ray diffractometer. The FTIR spectra were recorded using a Shimadzu FT-IR-8400 spectrometer. Raman measurements were performed at a wavelength of $514.5 \mathrm{~nm}$ using the Horiba LABAMHR spectrometer. The samples' compositional analysis was carried out using an X-ray photoelectron spectroscope (XPS-Omicron ESCA probe). The XPS spectra were deconvoluted by XPS Peak 4.1 program using the Gaussian-Lorentzian mixed function and Shirley background subtraction. The AFM images were obtained using a Nano Surf Easy Scan 2 AFM machine. The samples' surface morphology was studied by scanning electron microscopy (SEM-EDX -Joel model JSM-6390 LV).

\section{Results and Discussion}

The XRD profiles of the CS sample are presented in Fig.1. The sample shows a distinct, highly intense peaks at $\sim 24^{\circ}$ and a broadened peak around $42^{\circ}$ owing to (002) and (110) planes of graphite [27-31]. Comparing the XRD spectra of the samples with that of pure graphite (which shows only a single prominent peak at $\sim 26^{\circ}$ ), revealed a broadening of the peak. This is due to the effect of disorder in the $\mathrm{sp}^{2}$ hybridized carbon. The $\mathrm{sp}^{2}$ sites in the carbon will have both $\sigma$ and $\Pi$ states. The medium-range order due to $\Pi$-bonding distinguishes disordered carbons from the $\sigma$-bonded amorphous carbon. $\Pi$-bonding is maximized if the $\Pi$ states form pairs of aligned, or six-fold aromatic rings or graphitic clusters. This occurs in nano-crystalline graphitic carbon [31,33]. The presence of a strong and broadened $\Pi$ band in all the samples suggested that the carbon Nanospheres were composed of crystalline graphitic carbon with some defects.

The $\gamma$-band at $\sim 2 \Theta$ degree originates from disorder in the $\mathrm{sp}^{2}$ hybridized carbon and indicates lattice imperfection in the curve graphene sheets, spheres, and tube ends, etc. [32-37]. The comparatively low intensity of the $\gamma$-band in the XRD profile of the soot indicates that all the sources have a very low percentage of amorphous carbon. It is also noticed that there is a reduction in lateral dimension (La) with the modified Hummers method treatment $(7.33 \mathrm{~nm}$ to $4.14 \mathrm{~nm}$ for CS1). The stacking height is found to be increased from $2.76 \mathrm{~nm}$ to $3.10 \mathrm{~nm}$, indicating 10 layers of carbon.

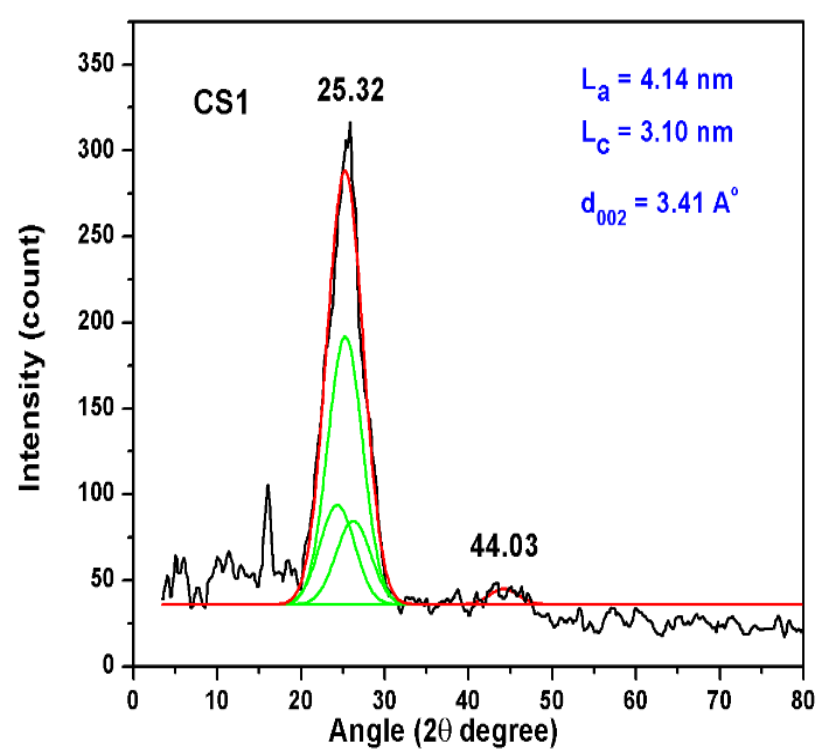

Figure 1. XRD analysis of camphor samples exhibiting formation nanostructure. 


\subsection{Atomic force microscopy of graphene layers.}

A typical AFM image of the obtained graphene is presented in Fig. 2. The cross-section height profile analysis indicates that CS1 samples consist of more than 10 layers.

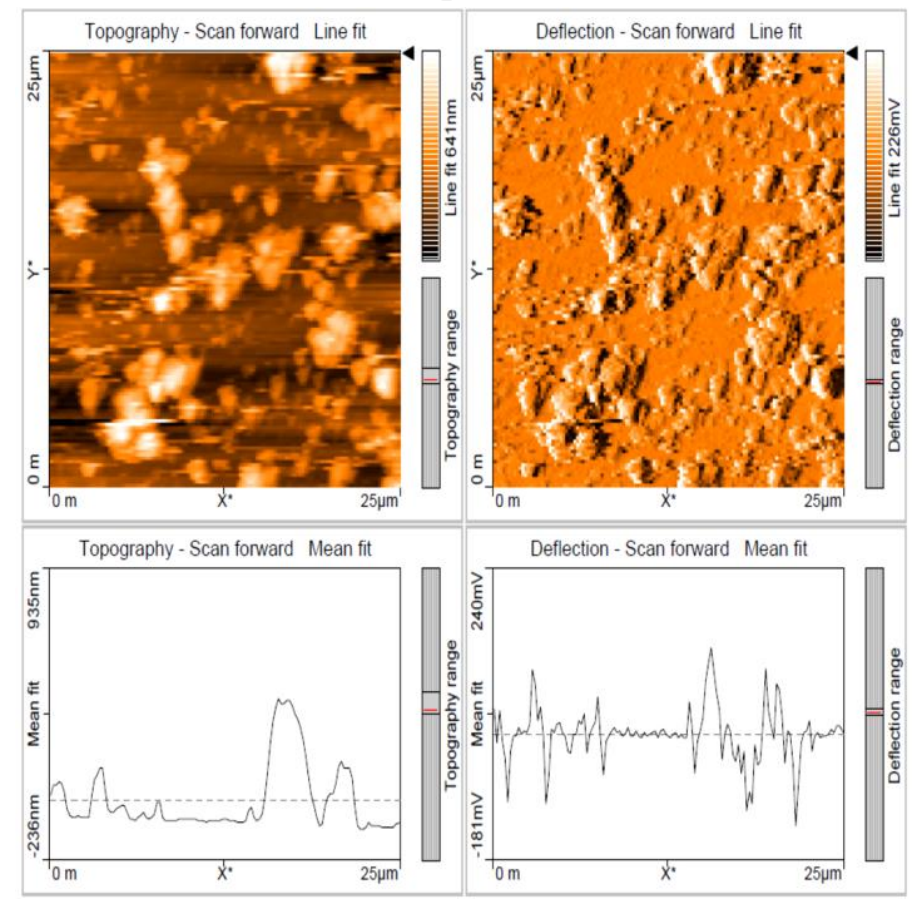

Figure 2. AFM analysis of CS1 sample exhibiting sheet-like structure.

The height profile confirms that the graphene layer formed is wrinkled or folded. The topography exhibited periodicity, confirming the development of a sheet-like structure. The forward scan fit displayed the height of the synthesized structure in the nanometer range.

\subsection{Scanning electron microscopy.}

The untreated samples' SEM image appears as agglomerated spheroids with irregularities with their diameter of about $100 \mathrm{~nm}$ and is presented in Fig.3. With Hummers' treatment, the development of layered structure with spheroids is observed on the surface. In the case of the CS1 sample, the nanosphere is open up, and a layered structure is formed, confirming the amorphous carbon's graphitization.

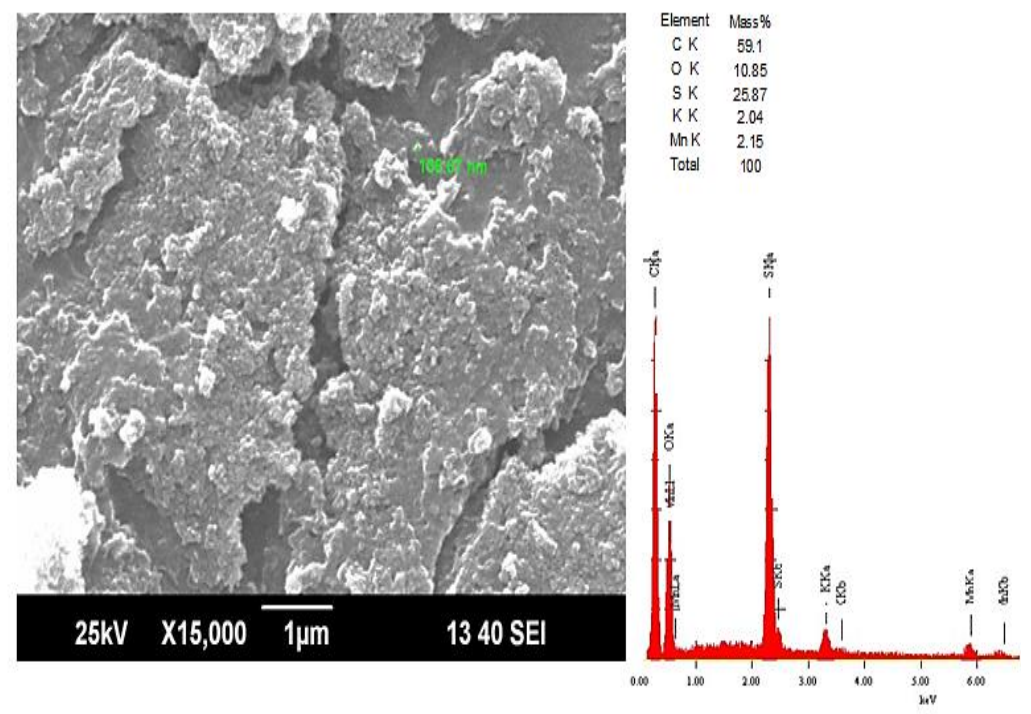

Figure 3. SEM-EDS analysis of nanostructure in the CS1 sample. 
EDS analysis was carried out to identify and quantify the constituents of the surface. The analysis reveals the presence of carbon with a little amount of oxygen in the untreated sample. But with the oxidation-reduction process, oxygen groups are incorporated in the microstructure along with elements like $\mathrm{Mn}, \mathrm{Si}, \mathrm{S}$, and $\mathrm{K}$, possibly from the chemicals used for the Hummers method.

\subsection{Raman analysis of graphene.}

Raman spectroscopy plays a vital role in the structural elucidation of graphitic materials, particularly graphene, by providing valuable information about its defects, stacking of layers, and crystallite size [37-42]. Raman fingerprints of single, bi- and few-layer graphene are different and investigated by many research groups [42-47]. The peak was observed at 1583 $\mathrm{cm}^{-1}$, due to the $\mathrm{G}$ band revealing high-frequency $\mathrm{E} 2 \mathrm{~g}$ first-order mode of graphite-like structure. The 2D band is very weak, indicating the stacking of layers in the nanostructure synthesized. The relative intensity ratio of the defect to the graphitic band is calculated as 0.95 and 0.98 for CS and CS1 samples, respectively, comparable with other reported results on graphene and graphite [47-50].

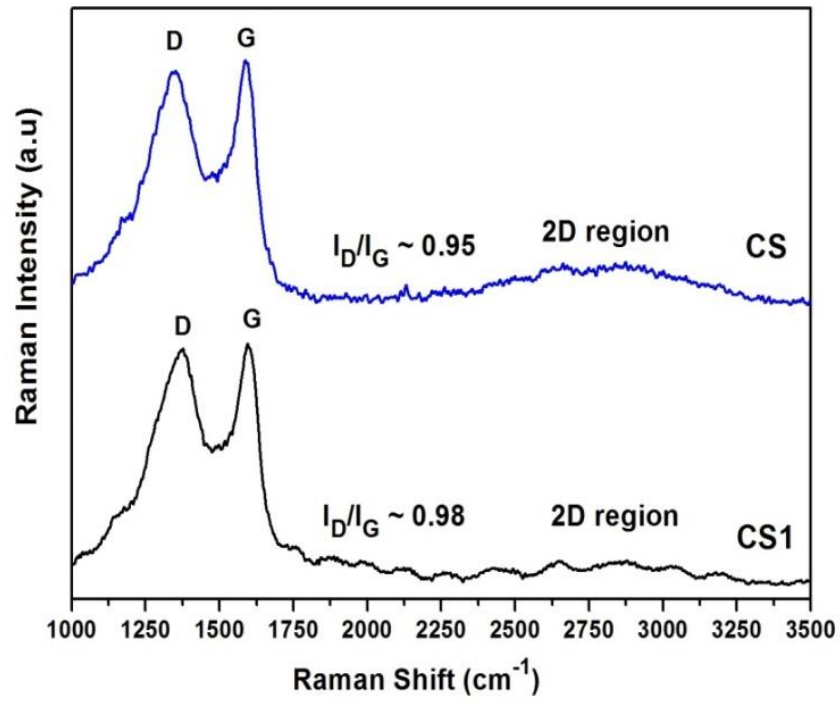

Figure 4. Raman anlysis of the nanostructure.

\subsection{XPS analysis of graphene.}

The C1s XPS spectrum of graphite oxide (In Fig. 5) indicates a considerable degree of oxidation with four components that correspond to carbon atoms in different functional groups; the non-oxygenated ring $\mathrm{C}$, the $\mathrm{C}$ in $\mathrm{C}-\mathrm{O}$ bonds, the carbonyl $\mathrm{C}$, and the carboxylate carbon [33]. The C1 s band of the GO sample (CS1 after Hummers' treatment) is fitted to four deconvoluted components, located at 284.7, 286.5, 287.3, and $289 \mathrm{eV}$. These components are assigned to non-oxygenated ring carbon ( $\mathrm{sp} 2$ carbon), $\mathrm{C}$ in $\mathrm{C}-\mathrm{O}$ (bound to $\mathrm{O}$ either as epoxy or hydroxyl), $\mathrm{C}$ in $\mathrm{C}=\mathrm{O}$ (of alcohols, phenols, or ether), and $\mathrm{C}$ in $\mathrm{C}(\mathrm{O}) \mathrm{O}$ (carboxylic acid), respectively which are separated by $1.8,0.8,1.7 \mathrm{eV}$ respectively. The components that experienced the highest degree of oxidation is the $\mathrm{C}$ in $\mathrm{COOH}$ and $\mathrm{C}-\mathrm{O}$ for the samples CS1 (This can be seen from the high-intensity peak around 289 and $286 \mathrm{eV}$ ). These X-ray photoelectron spectrometry results agree with IR, Raman, and XRD results, revealing that oxidation has happened to the graphene plane [47-52]. The observation is also consistent with the elemental analysis by EDS. 


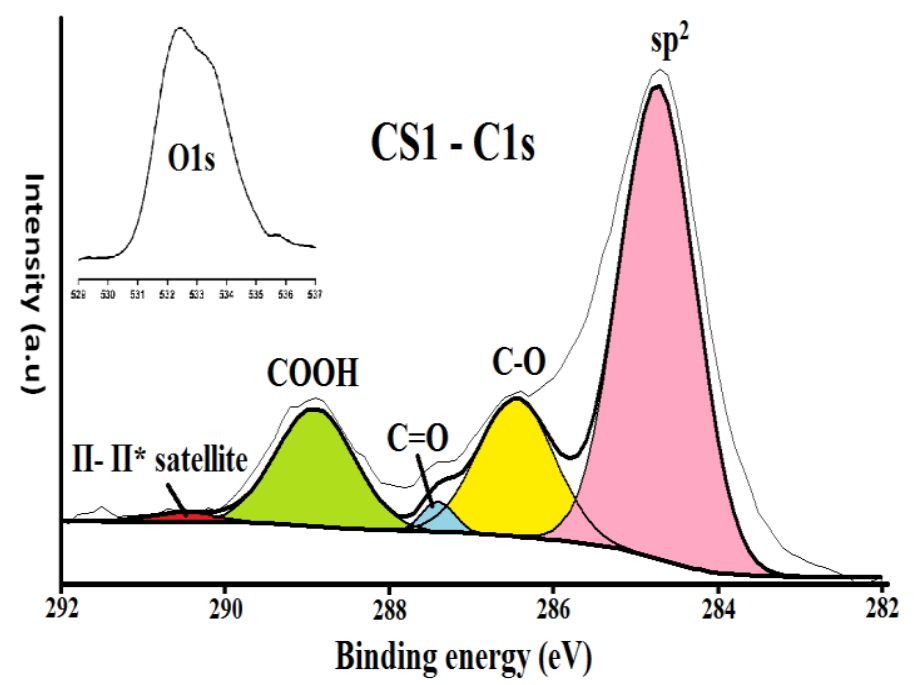

Figure 5. XPS analysis of the nanostructure CS1.

The inset of Fig.5 shows the high-resolution XPS spectrum of $\mathrm{O} 1 \mathrm{~s}$, which exhibits peak maximum at $532.5 \mathrm{eV}$, suggesting the presence of different bonding structures of $\mathrm{O}$. The component that experienced the highest degree of oxidation is the $\mathrm{C}$ in $\mathrm{COOH}$ for the CS1, as is evident from the high-intensity peak around $289 \mathrm{eV}$. The presence of the carboxylic group is least for the GS sample. These results in good agreement with the literature for similar $\mathrm{C} 1 \mathrm{~s}$ and band shapes for graphene oxide.

\subsection{FT-IR analysis of the graphene oxide.}

To investigate the thermal evolution and interactions of randomly distributed oxygen functional groups located both at the edges and on the basal plane, Fourier-transform infrared (FT-IR) spectroscopy was carried out on soot and carbonaceous products (spectra not shown). It is observed that modified Hummer's method leads to strong infrared absorbance associated with the $\mathrm{C}=\mathrm{O} / \mathrm{COOH}$ and $\mathrm{C}-\mathrm{OH}$ regions of multilayered $\mathrm{GO}$ with a sharp peak at 3000-3700 $\mathrm{cm}^{-1}$ due to larger hydroxyl, carboxyl, and water contribution [52-55]. The peak at $3431 \mathrm{~cm}^{-1}$ was assigned to the $\mathrm{O}-\mathrm{H}$ stretching vibrations and at $1047 \mathrm{~cm}^{-1}$ was due to the $\mathrm{C}-\mathrm{O}$ stretching vibrations. A sharp band is observed at $1500-1600 \mathrm{~cm}^{-1}$, which arises due to the asymmetric stretch of $\mathrm{sp}^{2}$ - hybridized $\mathrm{C}=\mathrm{C}$. Its intensity depends on the environment, being strongest with $\mathrm{C}=\mathrm{C}$ bonds and is attributed to the skeletal vibrations from graphitic domains, indicating the presence of crystalline graphitic carbon.

\section{Conclusions}

Several few-layer graphenes consisting of wrinkles and defects are synthesized from camphor, a botanical hydrocarbon. They are characterized using AFM, SEM, XRD, Raman spectroscopy, XPS, and FT-IR. From the AFM analysis, it is confirmed that the graphene layer formed is wrinkled or folded. The topography exhibited periodicity, confirming the development of a sheet-like structure. XRD analysis indicates the stacking of about 9-10 layers. The Raman analysis shows that the defect to graphitic peak intensity is less than 1 , indicating that the graphene layer's purity is better than the reported result using the graphite flake as precursors. The FTIR spectra reveal functional groups like carbonyl, carboxyl, and hydroxyl groups in the carbon matrix. The XPS analysis confirms the presence of carboxylic functional groups in the carbon matrix. In terms of the number of layers, crystallite size, and quality, 
reduced graphene oxide prepared from the camphor soot seems to be the best, possessing low defect to graphite band ratio and lesser number of layers.

\section{Funding}

This research received no external funding.

\section{Acknowledgments}

This work was financially supported by the Centre for Research-CHRIST(Deemed to be University). The authors are grateful to CHRIST (Deemed to be University) for providing lab facilities.

\section{Conflicts of Interest}

The authors declare no conflict of interest.

\section{References}

1. Venkatesan, R.A.; Balachandran, M. Novel carbon nano-onions from paraffinum liquidum for rapid and efficient removal of industrial dye from wastewater. Environmental Science and Pollution Research 2020, https://doi.org/10.1007/s11356-020-09981-w

2. Elazab, H.A.; Gadall, M.; Sadek, M.A.; El-Idreesy, T.T. Hydrothermal Synthesis of Graphene supported $\mathrm{Pd} / \mathrm{Fe} 3 \mathrm{O} 4$ Nanoparticles as an Efficient Magnetic Catalysts for Suzuki Cross-Coupling. Biointerface Research in Applied Chemistry 2019, 9, 2, https://doi.org/10.33263/BRIAC92.906911.

3. Liu, X.; Meng, Y.; Zhang, Z.; Wang, Y.; Geng, X.; Li, M.; Li, Z.; Zhang, D. Functional nano-catalyzed pyrolyzates from branch of Cinnamomum camphora. Saudi J. Biol. Sci. 2019, 26, 1227-1246, https://doi.org/10.1016/j.sjbs.2019.06.003.

4. Elmagzob, A.A.H.; Ibrahim, M.M.; Zhang, G.-F. Seasonal Diversity of Endophytic Bacteria Associated with Cinnamomum camphora (L.) Presl. Diversity 2019, 11, 112, https://doi.org/10.3390/d11070112.

5. Kang, N.-J.; Han, S.-C.; Yoon, S.-H.; Sim, J.-Y.; Maeng, Y.H.; Kang, H.-K.; Yoo, E.-S. Cinnamomum camphora leaves alleviate allergic skin inflammatory responses In Vitro and In Vivo. Toxicological research 2019, 35, 279-285, https://doi.org/10.5487/TR.2019.35.3.279.

6. Gong, K.; Pan, Y.; Rather, L.J.; Wang, W.; Zhou, Q.; Zhang, T.; Li, Q. Natural pigment during flora leaf senescence and its application in dyeing and UV protection finish of silk and wool -- a case study of Cinnamomum Camphora. Dyes and Pigments 2019, 166, 114-121, https://doi.org/10.1016/j.dyepig.2019.03.037.

7. Chen, Y.; Dai, G. Acaricidal activity of compounds from Cinnamomum camphora (L.) Presl against the carmine spider mite, Tetranychus cinnabarinus. Pest Manage. Sci. 2015, 71, 1561-1571, https://doi.org/10.1002/ps.3961.

8. Wu, L.; Xiong, W.; Hu, J.-W.; Wu, J.; Li, Z.-J.; Gao, Y.; Liu, D.; Liu, Y.; Liu, W.; Liang, M.; Si, C.-L.; Bae, Y.-S. Secondary Metabolites from the Twigs of Cinnamomum camphora. Chem. Nat. Compd. 2019, 55, 345347, https://doi.org/10.1007/s10600-019-02686-8.

9. Aunkor, M.T.H.; Mahbubul, I.M.; Saidur, R.; Metselaar, H.S.C. The green reduction of graphene oxide. Rsc Advances 2016, 6, 27807-27828, https://doi.org/10.1039/C6RA03189G.

10. Riya, T; Manoj, B. Luminescence and energy storage characteristics of coke-based graphite oxide. Materials Chemistry and Physics 2020, 123854, https://doi.org/10.1016/j.matchemphys.2020.123854.

11. Mohan, A.N.; Manoj, B. Surface modified graphene/SnO2 nanocomposite from carbon black as an efficient disinfectant against Pseudomonas aeruginosa. Mater. Chem. Phys. 2019, 232, 137-144, https://doi.org/10.1016/j.matchemphys.2019.04.074.

12. Zhu, C., S. Guo, Y. Fang, and S. Dong. Reducing sugar: new functional molecules for the green synthesis of graphene nanosheets. ACS Nano 2010, 4, 2429-2437, https://doi.org/10.1021/nn1002387.

13. Benoy, S.M.; Singh, S.; Pandey, M.; B, M. Characterization of nano-carbon based electrode material derived from anthracite coal. Materials Research Express 2020, 6, 125624, https://doi.org/10.1088/20531591/ab619d. 
14. Cui, Y.; Guo, X.; Lai, X.; Sun, H.; Liang, B.; Hou, W.; Liu, X.; Wang, L. Green Synthesis of JujubePolysaccharide-Stabilized Gold Nanoparticles for Reduction of 4-Nitrophenol. ChemistrySelect 2019, 4, 11483-11487, https://doi.org/10.1002/slct.201902531.

15. Zhong, X.; Wang, G.; Papandrea, B.; Li, M.; Xu, Y.; Chen, Y.; Chen, C.-Y.; Zhou, H.; Xue, T.; Li, Y.; Li, D.; Huang, Y.; Duan, X. Reduced graphene oxide/silicon nanowire heterostructures with enhanced photoactivity and superior photoelectrochemical stability. Nano Research 2015, 8, 2850-2858, https://doi.org/10.1007/s12274-015-0790-2.

16. Akhavan, O.; Kalaee, M.; Alavi, Z.S.; Ghiasi, S.M.A.; Esfandiar, A. Increasing the antioxidant activity of green tea polyphenols in the presence of iron for the reduction of graphene oxide. Carbon 2012, 50, 30153025, https://doi.org/10.1016/j.carbon.2012.02.087.

17. Nasrollahzadeh, M.; Mahmoudi-Gom Yek, S.; Motahharifar, N.; Ghafori Gorab, M. Recent Developments in the Plant-Mediated Green Synthesis of Ag-Based Nanoparticles for Environmental and Catalytic Applications. The Chemical Record 2019, 19, 2436-2479, https://doi.org/10.1002/tcr.201800202.

18. Thakur, S.; Karak, N. Green reduction of graphene oxide by aqueous phytoextracts. Carbon 2012, 50, 53315339, https://doi.org/10.1016/j.carbon.2012.07.023.

19. Novoselov, K.S.; Geim, A.K.; Morozov, S.V.; Jiang, D.; Zhang, Y.; Dubonos, S.V.; Grigorieva, I.V.; Firsov, A.A. Electric field effect in atomically thin carbon films. Science 2004, 306, 666-669, https://doi.org/10.1126/science.1102896.

20. Geim, A.K.; Novoselov, K.S. The rise of graphene. In Nanoscience and technology: a collection of reviews from nature journals, World Scientific: 2010; pp. 11-19, https://doi.org/10.1142/9789814287005-0002.

21. Chabot, V.; Higgins, D.; Yu, A.; Xiao, X.; Chen, Z.; Zhang, J. A review of graphene and graphene oxide sponge: material synthesis and applications to energy and the environment. Energy Environ. Sci. 2014, 7, 1564-1596, https://doi.org/10.1039/C3EE43385D.

22. Mohan, A.N.; B, M.; Panicker, S. Facile synthesis of graphene-tin oxide nanocomposite derived from agricultural waste for enhanced antibacterial activity against Pseudomonas aeruginosa. Sci. Rep. 2019, 9 , 4170, https://doi.org/10.1038/s41598-019-40916-9.

23. Rao, C.e.N.e.R.; Sood, A.e.K.; Subrahmanyam, K.e.S.; Govindaraj, A. Graphene: the new two-dimensional nanomaterial. Angew. Chem. Int. Ed. 2009, 48, 7752-7777, https://doi.org/10.1002/anie.200901678.

24. B, M.; Raj, A.M.; Chirayil, G.T. Tunable direct band gap photoluminescent organic semiconducting nanoparticles from lignite. Sci. Rep. 2017, 7, 18012, https://doi.org/10.1038/s41598-017-18338-2.

25. Janas, D. From Bio to Nano: A Review of Sustainable Methods of Synthesis of Carbon Nanotubes. Sustainability 2020, 12, 4115, https://doi.org/10.3390/su12104115.

26. Schedin, F.; Geim, A.K.; Morozov, S.V.; Hill, E.W.; Blake, P.; Katsnelson, M.I.; Novoselov, K.S. Detection of individual gas molecules adsorbed on graphene. Nature Materials 2007, 6, 652-655, https://doi.org/10.1038/nmat1967.

27. Hummers Jr, W.S.; Offeman, R.E. Preparation of graphitic oxide. J. Am. Chem. Soc. 1958, 80, 1339-1339, https://doi.org/10.1021/ja01539a017.

28. Tuinstra, F.; Koenig, J.L. Raman spectrum of graphite. The Journal of chemical physics 1970, 53, 1126-1130, https://doi.org/10.1063/1.1674108

29. Manoj, B.; Kunjomana, A.G. FT-Raman spectroscopic study of Indian bituminous and sub-bituminous coal. Asian Journal of Material Science 2010, 2, 204-210, https://doi.org/10.3923/ajmskr.2010.2014.210.

30. Manoj, B.; Raj, A.M.; Chirayil, G.T. Facile synthesis of preformed mixed nano-carbon structure from low rank coal. Materials Science-Poland 2018, 36, 14-20, https://doi.org/10.1515/msp-2018-0026.

31. Smajic, J.; Alazmi, A.; Costa, P.M.F.J. The Role of the Binder/Solvent Pair on the Electrochemical Performance of Aluminium Batteries. MRS Advances 2019, 4, 807-812, https://doi.org/10.1557/adv.2019.125.

32. Sadezky, A.; Muckenhuber, H.; Grothe, H.; Niessner, R.; Pöschl, U. Raman microspectroscopy of soot and related carbonaceous materials: Spectral analysis and structural information. Carbon 2005, 43, 1731-1742, https://doi.org/10.1016/j.carbon.2005.02.018.

33. Manoj, B. Synthesis and characterization of porous, mixed phase, wrinkled, few layer graphene like nanocarbon from charcoal. Russian Journal of Physical Chemistry A 2015, 89, 2438-2442, https://doi.org/10.1134/S0036024415130257

34. Abraham, J.E.; Das, A.K.; Pandey, M.; Balachandran, M. Synthesis of emeraldine PANI polymer-reduced graphene and its use as polyelectrolyte. Polym. Bull. 2020, 77, 4023-4041, https://doi.org/10.1007/s00289019-02954-1. 
35. Kumar, M.; Ando, Y. Single-wall and multi-wall carbon nanotubes from camphor-a botanical hydrocarbon. Diamond Relat. Mater. 2003, 12, 1845-1850, https://doi.org/10.1016/S0925-9635(03)00217-6.

36. Manoj, B.; Kunjomana, A.G. Systematic investigations of graphene layers in sub-bituminous coal. Russ. J. Appl. Chem. 2014, 87, 1726-1733, https://doi.org/10.1134/S1070427214110251.

37. Manoj, B. Characterization of nano-crystalline carbon from camphor and diesel by x-ray diffraction technique. Asian J. Chem. 2014, 26, 4553, http://dx.doi.org/10.14233/ajchem.2014.15150.

38. Dresselhaus, M.S.; Dresselhaus, G.; Saito, R.; Jorio, A. Raman spectroscopy of carbon nanotubes. Phys. Rep. 2005, 409, 47-99, https://doi.org/10.1016/j.physrep.2004.10.006.

39. Thomas, R.; Jayaseeli, E.; Sharma, N.M.S.; Manoj, B. Opto-electric property relationship in phosphorus embedded nano-carbon. Results in Physics 2018, 10, 633-639, https://doi.org/10.1016/j.rinp.2018.07.018.

40. Pandey, M.; Balachandran, M. Green Luminescence and Irradiance Properties of Carbon Dots Cross-linked with Polydimethylsiloxane. The Journal of Physical Chemistry C 2019, 123, 19835-19843, https://doi.org/10.1021/acs.jpcc.9b04130.

41. Iijima, S. Helical microtubules of graphitic carbon. Nature 1991, 354, 56-58, https://doi.org/10.1038/354056a0.

42. Ramya, K.; Manoj, B. Transformation of hydrocarbon soot to graphenic carbon nanostructures. Biointerface Research In Applied Chemistry 2018, 8, 3187-3192.

43. Mohan, A.N.; Manoj, B.; Ramya, A.V. Probing the nature of defects of graphene like nano-carbon from amorphous materials by Raman spectroscopy. Asian J. Chem. 2016, 28, 1501, https://doi.org/10.14233/ajchem.2016.19739

44. Iijima, S.; Yudasaka, M.; Yamada, R.; Bandow, S.; Suenaga, K.; Kokai, F.; Takahashi, K. Nano-aggregates of single-walled graphitic carbon nano-horns. Chem. Phys. Lett. 1999, 309, 165-170, https://doi.org/10.1016/S0009-2614(99)00642-9

45. Manoj, B.; Kunjomana, A.G. Structural characterization of selected Indian coals by X-ray diffraction and spectroscopic techniques. Trends in applied sciences research 2012, 7, 434-444, https://doi.org/10.3923/tasr.2012.434.444.

46. B, M.; Raj, A.M.; Thomas, G.C. Tailoring of low grade coal to fluorescent nano-carbon structures and their potential as a glucose sensor. Sci. Rep. 2018, 8, 13891, https://doi.org/10.1038/s41598-018-32371-9.

47. Manoj, B.; Narayanan, P. Study of changes to the organic functional groups of a high volatile bituminous coal during organic acid treatment process by FTIR spectroscopy. 2013, https://doi.org/10.4236/jmmce.2013.12008.

48. Pandey, M.; Balachandran, M. Flexible polymer composite films incorporated with Li-ion/reduced graphene oxide: excellent optical and photoluminescence performance. Applied Nanoscience 2020, 10, 401-410, https://doi.org/10.1007/s13204-019-01183-2.

49. Manoj, B.; Kunjomana, A.G. Structural characterization of graphene layers in various Indian coals by X-Ray Diffraction technique. IOP Conference Series: Materials Science and Engineering 2015, 73, 012096, https://doi.org/10.1088/1757-899X/73/1/012096.

50. Ramya, A.V.; Manoj, B.; Mohan, A.N. Extraction and characterization of wrinkled graphene nanolayers from commercial graphite. Asian J. Chem. 2016, 28, 1031, http://dx.doi.org/10.14233/ajchem.2016.19577.

51. Mohan, A.; Manoj, B. Extraction of graphene nanostructures from Colocasia esculenta and Nelumbo nucifera leaves and surface functionalization with tin oxide: Evaluation of their antibacterial properties. Chemistry-A European Journal 2020, https://doi.org/10.1002/chem.202000590.

52. Thomas, R.; Unnikrishnan, J.; Nair, A.V.; Elcey, C.D.; Manoj, B. Antibacterial performance of GO-Ag nanocomposite prepared via ecologically safe protocols. Appl Nanosci 2020, https://doi.org/10.1007/s13204020-01539-z.

53. Jicksy, J.; Gurumurthy, M.S.; Thomas, R.; Manoj B. Biosynthesized Ag Nanoparticles: a Promising Pathway for Bandgap Tailoring. Biointerface Research in Applied Chemistry 2020, 11, 8875-8883, https://doi.org/10.33263/BRIAC112.88758883.

54. Mohan, A.N.; Manoj, B. Biowaste derived graphene quantum dots interlaced with SnO 2 nanoparticles-a dynamic disinfection agent against Pseudomonas aeruginosa. New J. Chem. 2019, 43, 13681-13689, https://doi.org/10.1039/C9NJ00379G.

55. Mututu, V.; Sunitha, A.K.; Thomas, R.; Pandey, M.; Manoj, B. An Investigation on Structural, Electrical and Optical properties of $\mathrm{GO} / \mathrm{ZnO}$ Nanocomposite. Int. J. Electrochem. Sci 2019, 14, 3752-3763, https://doi.org/10.20964/2019.04.49. 